\title{
Norovirus outbreaks in long-term care facilities in Catalonia from 2017 to 2018
}

\author{
Ignacio Parrón ${ }^{1,2 \bowtie}$, Irene Barrabeig ${ }^{1,3}$, Miquel Alseda $^{4}$, Cristina Rius ${ }^{3,5}$, \\ Thais Cornejo-Sánchez ${ }^{6}$, Mireia Jané2 ${ }^{2,3,7}$, Cristina Pérez ${ }^{1}$, Susana Guix ${ }^{8,9}$, \\ Àngela Dominguez ${ }^{2,3}$ \& the Working Group for the Study of Outbreaks of Acute \\ Gastroenteritis in Catalonia*
}

Norovirus is the leading cause of outbreaks of acute viral gastroenteritis. We carried out this study to investigate outbreaks in long-term care facilities reported in 2017 and 2018 in Catalonia (Spain). The characteristics of the centers, exposed persons and the genogroups responsible were analyzed. Viral loads were estimated. The attack rate (AR) of the outbreaks studied, and the rate ratio (RR) and the odds ratio (OR) and their $95 \%$ confidence intervals as measures of association were calculated. The mean cycle thresholds were compared using the t-test for independent means. We included 30 outbreaks (4631 exposed people). The global AR was $25.93 \%$. The RR of residents vs. staff was 2.28 (95\% Cl 2.0-2.6). The RR between AR in residents with total or severe dependence vs. residents with moderate, low or no-dependence was 1.23 (95\% $\mathrm{Cl} 1.05-1.45)$. The AR were higher in smaller centers than in larger ones (38.47\% vs. $19.25 \%$ and $\mathrm{RR} 2 ; 95 \% \mathrm{Cl} 1.82-2.2)$. GII was responsible for $70 \%$ of outbreaks. No association was found between the genogroup and presenting symptoms (OR 0.96; $95 \% \mathrm{Cl} 0.41-2.26)$. Viral loads were higher in symptomatic than in asymptomatic patients $(p=0.001)$.

Norovirus, an RNA virus of the Caliciviridae family with 10 genogroups, of which genogroup I (GI), genogroup II (GII) and genogroup IV (GIV) are human pathogens ${ }^{1}$, usually produces symptoms of nausea, vomiting and diarrhea, with a self-limiting evolution of $48-72 \mathrm{~h}^{2}$.

Norovirus is estimated to be responsible for $20 \%$ of cases of all-cause diarrhea worldwide ${ }^{3}$ and may cause up to $90 \%$ of outbreaks of acute gastroenteritis (AGE) of viral etiology 4 .

Inns et al., in a review of norovirus reports worldwide between 1995 and 2015, found an incidence of up to 60 cases per 1000 person-years and a hospitalization rate of up to 1.04 per 1000 person-years ${ }^{5}$. Kreidieh et al. ${ }^{6}$ in a similar study in the Middle East and North Africa between 2000 and 2015 found that between $0.82 \%$ and $36.84 \%$ of AGE outbreaks in children aged $<5$ years treated in hospital emergency rooms were caused by norovirus.

Of the more than 1000 outbreaks of AGE reported annually in 2009 and 2010 in the United States, norovirus was confirmed as the etiological agent in $86 \%$, and $90 \%$ of norovirus-associated deaths occurred in people aged $\geq 65$ years $^{7}$.

In long-term care facilities (LTCF), the attack rate of AGE outbreaks due to norovirus varies between $3 \%$ and $45 \%$, with a case fatality rate ranging from $0.3 \%$ to $1.6 \%{ }^{8}$. In these institutions, norovirus is the second leading cause of outbreaks, after the influenza virus 9 . In England, an incidence of 30 outbreaks per 100 LTCF per year was reported in 2014-2016 ${ }^{10}$. In France in 2011, more than 70\% of AGE outbreaks in LTCF were due to norovirus ${ }^{11}$ and in the United States $>60 \%$ of norovirus outbreaks between 2009 and 2013 occurred in LTCF ${ }^{12}$. Although norovirus infection is usually mild, it may be more severe in older people. In developed countries, norovirus is responsible for between $10 \%$ and $20 \%$ of hospitalizations due to AGE in residents of LTCF and between $10 \%$ and $15 \%$ of deaths ${ }^{8}$.

${ }^{1}$ Sub-Direcció Regional a Barcelona del Departament de Salut, Barcelona, Spain. ${ }^{2}$ Departament de Medicina, Universitat de Barcelona, Barcelona, Spain. ${ }^{3} \mathrm{CIBER}$ Epidemiologia y Salud Pública, Instituto de Salud Carlos III, Madrid, Spain. ${ }^{4}$ Sub-Direcció Regional a Lleida del Departament de Salut, Lleida, Spain. ${ }^{5}$ Agència de Salut Pública de Barcelona, Barcelona, Spain. ${ }^{6}$ Departament de Microbiologia, Vall d'Hebrón Hospital, Barcelona, Spain. ${ }^{7}$ Sub-Direcció General de Vigilància i Resposta a Emergències de Salut Pública, Barcelona, Spain. ${ }^{8}$ Departament de Genètica Microbiologia i Estadística, Grup de Virus Entèrics, Universitat de Barcelona, Barcelona, Spain. ${ }^{9}$ Institut de Recerca en Nutrició i Seguretat Alimentària (INSA-UB), Universitat de Barcelona, Santa Coloma de Gramenet, Spain. *A list of authors and their affiliations appears at the end of the paper. ${ }^{\square}$ email: IParron@gencat.cat 
GII is the most frequently identified genogroup of norovirus in outbreaks ${ }^{13}$. In Spain, this genogroup has also been the most prevalent in recent years ${ }^{14}$.

Asymptomatic affected people may contribute to the transmission of norovirus ${ }^{15}$ and to a longer duration of outbreaks, which has important repercussions for disease control.

Symptomatic persons have a higher viral load than asymptomatic ones ${ }^{16}$, but no value has been established to predict the level of shedding associated with clinical manifestations ${ }^{17}$.

In symptomatic patients, it has not been possible to associate the duration of symptoms with the viral load, although the duration of viral shedding has been shown to be longer in those with a higher load and in older people ${ }^{18,19}$.

In patients with AGE, the viral load has been shown to be higher when symptoms are due to GII rather than GI, and the higher load of GII, which has been linked to increased ease of transmission ${ }^{20}$, has also been observed in patients co-infected with GI and GII ${ }^{16,18,21,22}$.

The objective of this study was to investigate attack rates in AGE outbreaks due to norovirus that occurred in LTCF and their association with the type of exposed person, the size of the center, the mode of transmission, the genogroup involved, and the viral load.

\section{Materials and methods}

A prospective study of outbreaks of AGE due to norovirus in LTCF reported between January 2017 and December 2018 was carried out in Catalonia, a region in Northeast Spain with a population of 7,496,276 in January 2017, of which $18.6 \%$ were aged $\geq 65$ years ${ }^{23}$ and 59,635 were residents of LTCF ${ }^{24}$.

Outbreaks of any etiology must be reported to the Public Health Agency of Catalonia, which studies the causes and establishes control measures ${ }^{25}$.

AGE was defined as sudden-onset diarrhea that may be accompanied by fever, nausea, vomiting, or abdominal pain. The involvement of $\geq 2$ people with a common exposure (or possible person-to-person transmission) was considered as an outbreak of AGE. A confirmed outbreak of norovirus was defined as the identification of norovirus in stool samples by real-time semiquantitative reverse transcription polymerase chain reaction (RTqPCR).

Two periods were defined: the warm months, lasting from April through September, and the cool months, lasting from October through March of the following year.

Data collection. All norovirus outbreaks occurring in LTCF confirmed by RTqPCR reported between January 2017 and December 2018 were included. The numbers of residents and staff (affected and unaffected), the capacity of the center and whether transmission was person-to-person or by a common vehicle were collected.

A survey was designed for exposed persons including sociodemographic data, the degree of dependence (estimated using the Barthel inde ${ }^{26}$ ), the history of heart disease, diabetes mellitus, dementia, immunodeficiency and chronic obstructive pulmonary disease, the date and time of symptom onset, the symptoms presented, hospitalization and death. For staff, information on the type of work was collected.

Stool sample analysis. Stool samples were collected to identify the cause of the outbreak. Norovirus was tested for using RTqPCR and identifying the genogroup detected. The semi-quantitative value given by the RTqPCR cycle of quantification $(\mathrm{Cq})$ was used to measure the viral load in samples positive for norovirus. Stool samples were obtained from symptomatic and asymptomatic staff and residents and, in outbreaks where foodborne transmission was suspected, from food handlers.

The analyses were made in the microbiology laboratories of the Vall Hebrón University Hospital and the Public Health Agency of Barcelona. Allplex GI-Virus Assay, Seegene Inc, was used to detect norovirus GI and GII. Samples positive for norovirus were genotyped using the primers described by Kojima et al. ${ }^{27}$. After the sequences were obtained, the Norovirus Typing Tool Version 2.0 (https://www.rivm.nl/mpf/typingtool/norov irus/) was used to obtain the genotype.

Statistical analysis. The attack rate (AR) by age group, sex, relation with the center (residents or staff), mode of transmission (person-to-person or foodborne), degree of dependency and, in staff, type of work activity were calculated. The rate ratio (RR) and $95 \%$ confidence intervals (CI) were calculated to estimate the risk of being affected globally and separately for sex, mode of transmission, the capacity of the center $(<100$ residents or $\geq 100$ residents) and the level of dependence (residents with total or severe dependence vs. residents with moderate, low or no-dependence).

To assess the seasonality, we used a one-tailed Z-test to compare the proportion of outbreaks in the cool months (October to March) with a theoretical value of $50 \%$. The correlation between the average temperature of each month in Barcelona ${ }^{28}$ and the number of outbreaks in the month was estimated using Pearson's correlation coefficient and the $p$ value with a t-Student test.

A one-tailed Fisher's exact test was used to compare the proportion of residents affected with specific underlying diseases (heart disease, diabetes mellitus, dementia, immunodeficiency and chronic obstructive pulmonary disease) with the proportion of residents without these underlying diseases. This test was also used to compare the proportion of residents and staff members who needed medical care. The association between genogroup and the presence of symptoms was assessed using the odds ratio (OR) and its $95 \%$ CI.

The mean Cq, as an approximation to the viral load, was compared in symptomatic and asymptomatic infected persons (in staff, residents and all attenders) using the t-test for independent means. The Student's t-test and its $95 \%$ CI was used to calculate the degree of significance of the difference between means. A Hartley's $F_{\max }$ test for variance homogeneity was used previously and if the $p$ value of the $\mathrm{F}_{\max }$ statistic was $>0.05$, the $\mathrm{t}$-test was based on equal variance; otherwise, the t-test was based on unequal variance. 


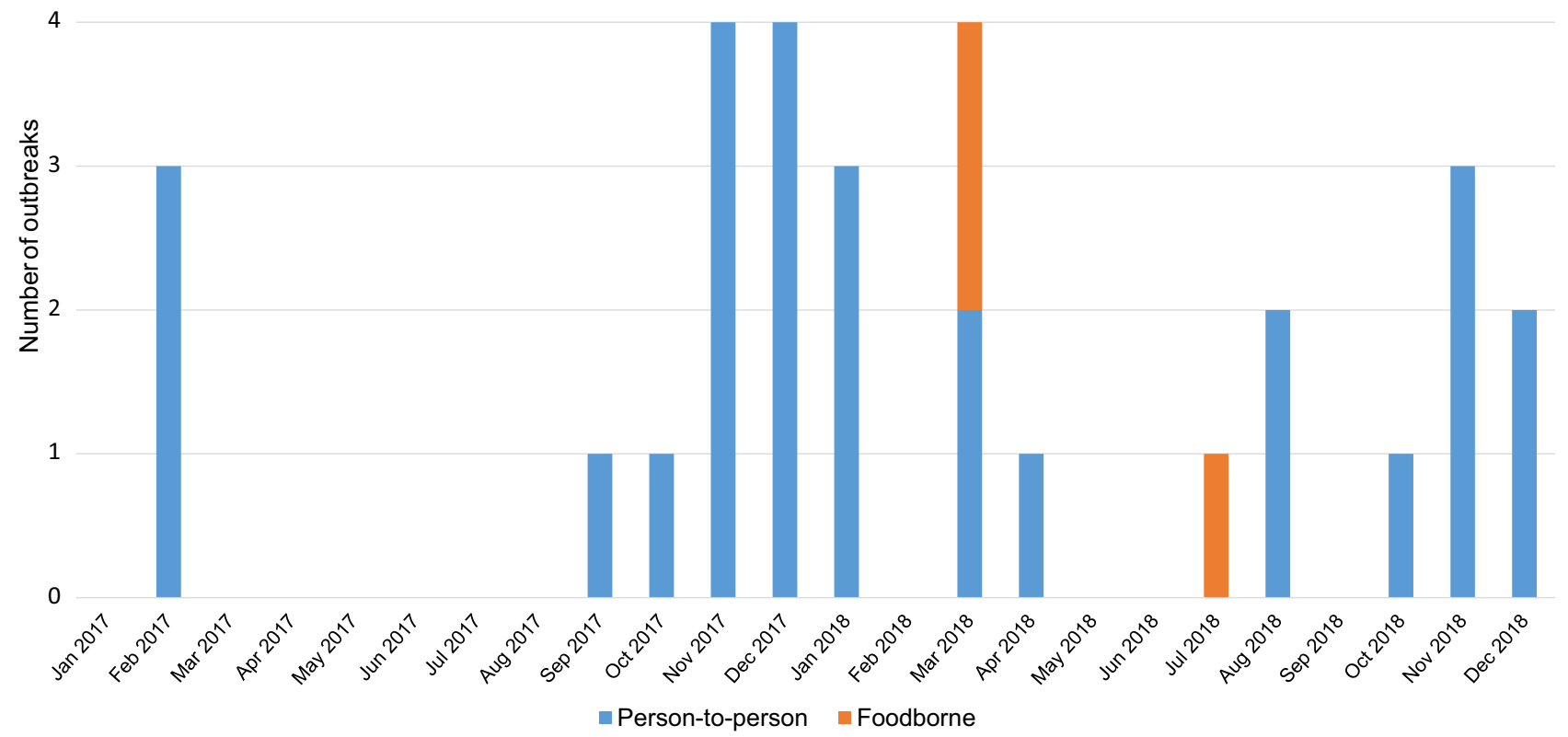

Figure 1. Number of acute gastroenteritis outbreaks due to norovirus in long-term care facilities according to the month of onset and mode of transmission.

Data collection and management was made using the MS-Office 2013 Access 12.0 database and the statistical analysis using the PASW Statistics 18.0.2 statistical package and Epi Info for Windows 7.2.

Ethics declarations and informed consent statement. The study was conducted according to the guidelines of the Declaration of Helsinki, regulations of the Public Health Agency of Catalonia and ethical protocols established. The study was approved by the University of Barcelona Bioethics Commission (ethics approval number IRB00003099) on April 12, 2016.

The authors declare that the Bioethics Committee of University of Barcelona approved the waiver for informed consent. All data used in the analysis were collected during routine public health surveillance activities as part of the legislated mandate of the Health Department of Catalonia, which is officially authorized to receive, treat and temporarily store personal data in the case of infectious disease. All data were fully anonymized. All study activities formed part of the public health surveillance tasks. The law regulates these activities and informed consent should not be necessary.

\section{Results}

Reported outbreaks. During the study period, 213 AGE outbreaks were reported to the Public Health Agency of Catalonia; 40 (18.78\%) occurred in LTCF and norovirus was identified as the causal agent in $75 \%$ $(30 / 40)$.

The transmission mode was person-to-person in 27 of the 30 outbreaks in LTCF and foodborne in the remaining three, although there was also subsequent person-to-person transmission in one foodborne outbreak. In these three foodborne outbreaks, four kitchen workers were affected ( 3 cooks and 1 kitchen assistant).

A total of 4631 persons were exposed and 1201 of these were affected (AR 25.93\%); 3,034 exposed persons were LTCF residents, of whom 976 were affected (AR 32.17\%). Of the 1597 exposed staff members, 225 were affected (AR 14.09\%). The RR for residents vs. staff members was 2.28 (95\% CI 2.0-2.61).

In person-to-person transmission outbreaks, 4170 persons were exposed and 1048 were affected (AR 25.13\%). Among residents, the AR was $32.48 \%$ (2768 exposed and 899 affected) and among staff members it was $10.63 \%$ (1402 exposed and 149 affected) (RR 3.06 95\% CI 2.60-3.59).

In foodborne outbreaks, the overall AR was 33.19\% (461 exposed and 153 affected), and it was $28.95 \%$ (266 exposed and 77 affected) among residents and 38.97\% (195 exposed and 76 affected) among staff (RR 0.74; 95\% CI 0.57-0.96).

Twenty-five (83.33\%) outbreaks occurred in the cool months and five (16.67\%) in the warm months. There was a significantly higher proportion of outbreaks in the cool months (z-test $=3.61, p<0.001)$. In addition, a Pearson's correlation coefficient of $-0.63(p=0.03)$ between the average temperature and the number of outbreaks per month was observed. Of the 27 outbreaks with person-to-person transmission, $13(48.15 \%)$ occurred during the colder months (December to March) (Fig. 1). 


\begin{tabular}{|l|l|l|l|l|l|l|l|}
\hline & \multicolumn{3}{|l|}{ Centers with $<\mathbf{1 0 0}$ residents } & \multicolumn{2}{l|}{ Centers with $\geq \mathbf{1 0 0}$ residents } & \multirow{2}{*}{ (95\% CI) } \\
\cline { 2 - 7 } & Affected & Unaffected & Attack rate & Affected & Unaffected & Attack rate & RR (95. \\
\hline Residents & 508 & 616 & 45.2 & 468 & 1442 & 24.5 & $1.85(1.67-2.04)$ \\
\hline Staff & 111 & 374 & 22.89 & 114 & 998 & 10.25 & $2.23(1.76-2.83)$ \\
\hline Total exposed & 619 & 990 & 38.47 & 582 & 2440 & 19.26 & $2(1.82-2.2)$ \\
\hline
\end{tabular}

Table 1. Attack rates and rate ratio (RR) according to the capacity of the facility (separately for residents and staff and globally).

\begin{tabular}{|l|l|l|l|l|}
\hline Degree of dependency & Affected residents & Unaffected residents & Attack rate (\%) & RR (95\% CI) \\
\hline Total dependency (0-20) & 45 & 13 & 77.59 & \\
\hline Severe dependency (21-60) & 87 & 10 & 89.69 & \\
\hline Moderate dependency (61-90) & 48 & 22 & 68.57 & \\
\hline Low dependency (91-99) & 5 & 2 & 71.43 & \multirow{2}{*}{$1.23(1.05-1.45)$} \\
\hline Independent (100) & 3 & 1 & 75 & 1 \\
\hline Total + severe & 132 & 23 & 85.16 & 69.13 \\
\hline Moderate + low + No dependence & 56 & 25 & & 1 \\
\hline
\end{tabular}

Table 2. Degree of dependency (Barthel index) in affected and unaffected residents, attack rates and rate ratio $(\mathrm{RR})$ in residents with total or severe dependence versus residents with moderate, low or no-dependence.

Of the centers where outbreaks occurred, 13 had a capacity of $\geq 100$ residents and the AR was $19.26 \%$. The remaining 17 centers had a capacity of $<100$ residents and the AR was $38.47 \%$. The RR, both globally and for staff or residents, indicated an increased risk of being affected in smaller centers (Table 1).

Results of the survey in exposed and affected persons in LTCF. A total of 495 exposed persons (365 residents and 130 staff) were interviewed, of whom 106 (21.41\%) were male and $389(78.59 \%)$ female. The average age was 86.20 years (SD 8.87) in residents and 40.14 years (SD 13.44) in staff. Nine residents aged $<65$ years were affected (AR 88.89\%), 64 aged 65-74 years (AR 84.21\%), 158 aged 85-94 years (AR 82.29\%) and 36 aged 95-105 years (AR 83.72\%). In staff members, there were 38 affected persons aged 18-39 years (AR 65.52\%) and 34 aged 40-65 years (AR 53.97\%). The age was unknown in 20 residents and 9 staff members.

Of the total exposed people interviewed, 371 persons were affected (295 residents and 76 staff members) and 124 unaffected. Nine residents and 13 staff members needed medical care (3.05\% of affected residents and $17.11 \%$ of affected staff members), with the difference being significant $(p<0.001)$. Four affected persons $(1.08 \%$ of all affected people) were hospitalized: 3 residents (1.02\% of residents affected) and 1 staff member $(1.32 \%$ of staff members affected). The difference was not significant $(p=0.60)$. No deaths were recorded.

The AR was $72.64 \%$ in males (106 exposed and 77 affected) and $75.58 \%$ in females ( 389 exposed, 294 affected) (RR 0.96; 95\% CI 0.84-1.09).

The AR was 76.55\% in person-to-person outbreaks (388 exposed, 297 affected) and 69.16\% (107 exposed, 74 affected) in foodborne outbreaks (RR 1.11; 95\% CI 0.96-1.27).

Information on underlying diseases was obtained in 305 (83.56\%) residents of whom 255 were affected. The proportion of residents with and without a specific underlying disease who were affected were compared: for heart disease these proportions were $86.33 \%$ and $81.33 \%(p=0.15)$; for diabetes mellitus $82.89 \%$ and $64.21 \%$ $(p=0.49)$; for dementia $81.03 \%$ and $84.21 \%(p=0.34)$; for immunodeficiency $81.82 \%$ and $83.67 \%(p=0.56)$; for chronic obstructive pulmonary disease $76.74 \%$ and $84.73 \%(p=0.14)$. The degree of dependence (measured by the Barthel index) was obtained in 236 residents (188 affected and 48 unaffected). The AR was $85.16 \%$ in residents with total or severe dependence and $69.13 \%$ in residents with moderate, low or no-dependence (RR 1.23 ; 95\% CI 1.05-1.45) (Table 2).

Information on occupation was obtained for 123 staff members: 58 were maintenance personnel or kitchen staff (of whom 26 were affected) and 65 were healthcare staff or caregivers (of whom 49 were affected); in 7 staff members this information was not available. Kitchen staff and maintenance personnel had a lower risk of being affected than healthcare staff and caregivers (RR 0.59; 95\% CI 0.43-0.82) (Table 3).

Of the 30 outbreaks studied, 5 were due to GI (16.67\%), 21 to GII (70\%) and the remaining $4(13.33 \%)$ were due to mixed infection by GI and GII. We identified 35 genotypes: GII.4 was identified in 13 outbreaks, GII.17 in five, GI.6 in three, and GI.3, GI.4, GII.2 and GII.P16 in two outbreaks. The remaining genotypes (GI.2, GI.5, GI.P4, GI.P5, GII.P7, GII.P17 and GII.P31) were identified in one outbreak.

A total of 425 stool samples were collected and norovirus was identified by RTqPCR in 256. GI was identified in 53 samples (20.70\%) and GII in 198 samples (77.34\%). In 5 samples (1.95\%) coinfection with GI and GII (2 symptomatic and 3 asymptomatic) was identified. The remaining 169 samples were negative for norovirus. 


\begin{tabular}{|l|l|l|l|l|}
\hline Occupation & Affected & Unaffected & Attack rate (\%) & RR (95\% CI) \\
\hline Kitchen staff and service personnel & 26 & 32 & 44.83 & $0.59(0.43-0.82)$ \\
\hline Health staff and caregivers & 49 & 16 & 75.38 & 1 \\
\hline Total & 75 & 48 & 60.98 & \\
\hline
\end{tabular}

Table 3. Attack rates and rate ratio (RR) in long-term care facilities staff according to occupation.

\begin{tabular}{|l|l|l|l|l|}
\hline Genogroup & Symptomatic & Asymptomatic & Total & OR (95\% CI) \\
\hline GI & 45 & 8 & 53 & $0.96(0.41-2.26)$ \\
\hline GII & 169 & 29 & 198 & 1 \\
\hline
\end{tabular}

Table 4. Norovirus genogroup in symptomatic and asymptomatic infected long-term care facilities staff and residents.

\begin{tabular}{|c|c|c|c|c|c|}
\hline & Symptomatic & Mean (SD) & Positive samples $^{*}$ & $\begin{array}{l}\text { Difference between means of } \mathrm{Cq} \\
(95 \% \mathrm{CI})\end{array}$ & $p$ Value \\
\hline \multirow{2}{*}{ Staff } & Yes & $28.11(5.54)$ & 46 & \multirow{2}{*}{$\begin{array}{l}-1.85 \\
(-4.87 \text { to } 1.17)\end{array}$} & \multirow{2}{*}{0.225} \\
\hline & No & $29.96(5.15)$ & 18 & & \\
\hline \multirow{2}{*}{ Residents } & Yes & $24.96(5.87)$ & 164 & \multirow{2}{*}{$\begin{array}{l}-3.19 \\
(-5.82 \text { to }-0.56)\end{array}$} & \multirow{2}{*}{0.018} \\
\hline & No & $28.15(5.84)$ & 22 & & \\
\hline \multirow{2}{*}{ All persons } & Yes & $25.65(5.93)$ & 210 & \multirow{2}{*}{$\begin{array}{l}-3.35 \\
(-5.34 \text { to }-1.35)\end{array}$} & \multirow{2}{*}{0.001} \\
\hline & No & $29.00(5.50)$ & 40 & & \\
\hline
\end{tabular}

Table 5. Quantification cycle $(\mathrm{Cq})$ values in symptomatic and asymptomatic infected staff and residents of long-term care facilities. ${ }^{\star}$ In 6 samples positive for GII norovirus, the Cq value could not be determined.

Table 4 shows the genogroup detected in symptomatic and asymptomatic infected LTCF staff and residents. No association was found between the genogroup and presenting symptoms (OR 0.96; 95\% CI 0.41-2.26), indicating that the proportion of asymptomatic infections was similar for both genogroups.

With respect to the viral load in symptomatic and asymptomatic persons (Table 5), the difference between the means of the Cq was -3.35 (95\% CI -5.34 to -1.35$)$, with a greater viral load found in symptomatic than in asymptomatic persons $(p=0.001)$.

\section{Discussion}

Our results show that $18.78 \%$ of AGE outbreaks occurred in LTCF, similar to the results obtained by Torner et al. ${ }^{29}$ in a study carried out in Catalonia in 2010 and 2011.

Norovirus was identified as the cause of $75 \%$ of the 40 outbreaks occurring in LTCF, coinciding with results from other studies. Inns et al. described 566 AGE outbreaks in LTCF in Northeast England between 2016 and 2018 and norovirus was detected in $64 \%$ of outbreaks with an identified pathogen ${ }^{30}$. Steele et al. ${ }^{31}$ studied 7094 norovirus outbreaks between 2009 and 2017 in the United States of which 5335 (75\%) occurred in LTCF and Espenhain et al. found that $77 \%$ of norovirus outbreaks in Norway between 2005 and 2018 occurred in LTCF LT $^{32}$.

A seasonal distribution was observed, with most outbreaks occurring in the cool months. Our results are consistent with previous findings by other authors indicating a seasonality of norovirus disease $\mathrm{e}^{4,33}$.

The mode of transmission of the outbreaks studied showed there was person-to-person transmission in $90 \%$ and only $10 \%$ were foodborne. Similar results were found by Kroneman et al. in a study of norovirus outbreaks in 13 European countries between July 2001 and June 2006 (person-to-person transmission accounted for $88 \%$ of outbreaks, $10 \%$ were foodborne and $2 \%$ were food and waterborne) ${ }^{34}$. We found no outbreaks due to waterborne transmission. Chen et al. in a review of norovirus outbreaks in LTCF found person-to-person transmission in $>90 \%$ of outbreaks and linked this to close contact with other residents, shared facilities and contact with visitors and staff ${ }^{35}$. Lian et al. ${ }^{4}$ in an analysis of norovirus outbreaks reported in China from 2014 to 2017 found that $77 \%$ were caused by person-to-person transmission, $6 \%$ foodborne, $4 \%$ waterborne and $13 \%$ by multiple transmission.

Hospitalization was required in $1.08 \%$ of affected people, coinciding with Espenhaim et al. ${ }^{32}$ in a Norwegian study carried out during 2005-2018, who reported $0.91 \%$ of hospitalizations in affected people.

No deaths were reported in the norovirus outbreaks included in this study, coinciding with the results of the Lian et al. study carried out in China in a four-year period ${ }^{4}$. However, Espenhaim et al. ${ }^{32}$ reported $0.67 \%$ of deaths in LTCF outbreaks in the above-mentioned period of 13 years. 
Our results suggest that the closeness of contact between residents and staff may play an important role in the transmission, as staff who had greater contact with residents (healthcare staff and caregivers) had an increased risk of being affected than those who did not. A 2014 meta-analysis by Petrignani et al. ${ }^{36}$ of 40 outbreaks in LTCF also found that the closeness of contact between staff and residents was related to the risk of staff being affected. The authors found that residents with medium or high dependence had a higher attack rate than those with low dependence. Our results showed that $70.21 \%$ of affected residents had total or severe dependence (Barthel score between 0 and 60) in agreement with the results obtained by these authors, suggesting that people with greater dependence require greater contact with caregivers.

Norovirus was identified by RTqPCR in the stool samples of $36.70 \%(40 / 109)$ of asymptomatic exposed persons, similar to the values estimated by Miura et al. in foodborne outbreaks in Japan from 2005 to 2006 in which they identified norovirus in $32.1 \%$ of asymptomatic persons ${ }^{37}$.

We found that symptomatic infected persons had a higher viral load, with a mean Cq of 25.65, compared with 29.00 in asymptomatic infected persons. These results are similar to those obtained by Shioda et al., who studied 12,910 samples from outbreaks and isolated cases in the United States and Latin America with a mean Cq of 25.3 for symptomatic affected persons and 28.5 for asymptomatic affected persons ${ }^{18}$.

We found that outbreaks in centers with a lower capacity had a higher attack rate than outbreaks in centers with greater capacity. A possible explanation is that, in smaller centers, the cleaning and disinfection protocols when outbreaks occur may be less developed than in large centers. Rosenthal et al. in a study conducted in Oregon between 2003 and 2006, found contrary results ${ }^{38}$, with the differences possibly being due to characteristics of the centers that were not recorded.

A strength of the study is that all outbreaks reported in a region with the same surveillance system were included, and therefore the results should be homogeneous and reflect the real situation.

Our study has some limitations. First, the mild severity of AGE outbreaks due to norovirus means underreporting may be greater in small centers than in large ones as, because there are fewer cases, contact with the health services and notification of the outbreak may be less likely. Secondly, we did not collect information about staff working closely with residents with different levels of dependence and, therefore, we could not analyze whether there was a relationship between these variables. Another limitation is that the number of samples from infected asymptomatic persons was low, meaning there was not sufficient statistical power to detect differences with symptomatic persons.

\section{Conclusions}

Norovirus caused the vast majority of AGE outbreaks in LTCF, with more residents than staff being affected, especially those with a high degree of dependence. Person-to-person transmission was the main mode of transmission and GII was the most prevalent causal agent. There was no outbreak caused by GIV.

Mean viral loads were higher in infected symptomatic persons than in infected asymptomatic persons, both globally and in residents. Because norovirus was detected in asymptomatic persons, control measures should be applied not only to people with symptoms but to all persons in LTCF where norovirus outbreaks occur.

\section{Data availability}

The datasets generated during the current study are available in the Mendeley Data repository (https://data. mendeley.com/datasets/58pjx5vpk2/1).

Received: 13 February 2021; Accepted: 10 November 2021

Published online: 01 December 2021

\section{References}

1. Chhabra, P. et al. Updated classification of norovirus genogroups and genotypes. J. Gen. Virol. 100, 1393-1406. https://doi.org/10. 1099/jgv.0.001318 (2019).

2. Heyman, D. L. (ed.) Control of Communicable Diseases Manual 20th edn, 436-441 (American Public Health Association, 2015).

3. Ahmed, S. M. et al. Global prevalence of norovirus in cases of gastroenteritis: A systematic review and meta-analysis. Lancet Infect. Dis. 14, 725-730. https://doi.org/10.1016/S1473-3099(14)70767-4 (2014).

4. Lian, Y. et al. Epidemiology of norovirus outbreaks reported to the Public Health Emergency Event Surveillance System, China, 2014-2017. Viruses 11, 342. https://doi.org/10.3390/v11040342 (2019).

5. Inns, T., Harris, J., Vivancos, R., Iturriza-Gomara, M. \& O'Brien, S. Community-based surveillance of norovirus disease: A systematic review. BMC Infect. Dis. 17, 657. https://doi.org/10.1186/s12879-017-2758-1 (2017).

6. Kreidieh, K., Charide, R., Dbaibo, G. \& Melhem, N. M. The epidemiology of norovirus in the Middle East and North Africa (MENA) region: a systematic review. Virol. J. 14, 220. https://doi.org/10.1186/s12985-017-0877-3 (2017).

7. Trivedi, T. K. et al. Hospitalizations and mortality associated with norovirus outbreaks in nursing homes, 2009-2010. JAMA 308, 1668-1675. https://doi.org/10.1001/jama.2012.14023 (2012).

8. Lindsay, L., Wolter, J., De Coster, I., Van Damme, P. \& Verstraeten, T. A decade of norovirus disease risk among older adults in upper-middle and high income countries: A systematic review. BMC Infect. Dis. 15, 425. https://doi.org/10.1186/s12879-015-1168-5 (2015).

9. Gaspard, P. et al. Gastroenteritis and respiratory infection outbreaks in French nursing homes from 2007 to 2018: Morbidity and all-cause lethality according to the individual characteristics of residents. PLoS ONE 14, e0222321. https://doi.org/10.1371/journ al.pone.0222321 (2019).

10. Inns, T. et al. Estimating the burden of care home gastroenteritis outbreaks in England, 2014-2016. BMC Infect. Dis. 19, 12. https:// doi.org/10.1186/s12879-018-3642-3 (2019).

11. Barret, A. S. et al. Surveillance for outbreaks of gastroenteritis in elderly long-term care facilities in France, November 2010 to May 2012. Euro Surveill. 19, 20859. https://doi.org/10.2807/1560-7917.es2014.19.29.20859 (2014).

12. Vega, E. et al. Genotypic and epidemiologic trends of norovirus outbreaks in the United States, 2009 to 2013. J. Clin. Microbiol. 52, 147-155. https://doi.org/10.1128/JCM.02680-13 (2014). 
13. van Beek, J. et al. Molecular surveillance of norovirus, 2005-16: An epidemiological analysis of data collected from the NoroNet network. Lancet Infect. Dis. 18, 545-553. https://doi.org/10.1016/S1473-3099(18)30059-8 (2018).

14. Sabrià, A. et al. Norovirus shedding among food and healthcare workers exposed to the virus in outbreak settings. J. Clin. Virol. 82, 119-125. https://doi.org/10.1016/j.jcv.2016.07.012 (2016).

15. Gastañaduy, P. A. et al. Transmission of norovirus within households in Quininde, Ecuador. Pediatr. Infect. Dis. J. 34, 1031-1033. https://doi.org/10.1097/INF.0000000000000783 (2015).

16. Costantini, V. P. et al. Epidemiologic, virologic, and host genetic factors of norovirus outbreaks in long-term care facilities. Clin. Infect. Dis. 62, 1-10. https://doi.org/10.1093/cid/civ747 (2016).

17. Kabue, J. P., Meader, E., Hunter, P. R. \& Potgieter, N. Norovirus prevalence and estimated viral load in symptomatic and asymptomatic children from rural communities of Vhembe district, South Africa. J. Clin. Virol. 84, 12-18. https://doi.org/10.1016/j.jcv. 2016.09.005 (2016).

18. Shioda, K. et al. Can use of viral load improve norovirus clinical diagnosis and disease attribution?. Open Forum Infect. Dis. 4, ofx131. https://doi.org/10.1093/ofid/ofx131 (2017).

19. Partridge, D. G., Evans, C. M., Raza, M., Kudesia, G. \& Parsons, H. K. Lessons from a large norovirus outbreak: Impact of viral load, patient age and ward design on duration of symptoms and shedding and likelihood of transmission. J. Hosp. Infect. 81, 25-30. https://doi.org/10.1016/j.jhin.2012.02.002 (2012).

20. Chan, M. C. et al. Fecal viral load and norovirus-associated gastroenteritis. Emerg. Infect. Dis. 12, 1278-1280. https://doi.org/10. 3201/eid1208.060081 (2006).

21. Chan, M. C. et al. Virus genotype distribution and virus burden in children and adults hospitalized for norovirus gastroenteritis, 2012-2014, Hong Kong. Sci. Rep. 5, 11507. https://doi.org/10.1038/srep11507 (2015).

22. He, T. et al. Norovirus loads in stool specimens of cancer patients with norovirus gastroenteritis. J. Mol. Diagn. 19, 836-842. https:// doi.org/10.1016/j.jmoldx.2017.06.006 (2017).

23. Statistical Institute of Catalonia. Population on 1 January. By sex. https://www.idescat.cat $/$ indicadors $/$ id $=$ anuals\&n=10328\&col= $1 \&$ lang=en. Accessed 18 Oct 2020.

24. Facilities for the elderly. Residences. By ownership. Counties and Aran, areas and provinces. https://www.idescat.cat/pub/?id= aec\&n=849\&t=2017\&lang=en. Accessed 14 Aug 2021.

25. Generalitat de Catalunya. Decret 203/2015 de 15 de setembre, pel qual es crea la Xarxa de Vigilància Epidemiològica i es regulen els sistemes de notificació de malalties de declaració obligatòria i brots epidèmics. Diari Oficial de la Generalitat de Catalunya, Núm 6958,1-19. https://portaldogc.gencat.cat/utilsEADOP/PDF/6958/1444533.pdf. Accessed 26 Nov 2020.

26. Mahoney, F. I. \& Barthel, D. Functional evaluation: The Barthel index. Md. State Med. J. 14, 61-65 (1965).

27. Kojima, S. et al. Genogroup-specific PCR primers for detection of Norwalk-like viruses. J. Virol. Methods 100, 107-114. https:// doi.org/10.1016/s0166-0934(01)00404-9 (2002).

28. Ajuntament de Barcelona. El Temps: El clima de Barcelona. https://www.barcelona.cat/temps/ca/climatologia/clima_barcelona. Accessed 24 Aug 2021.

29. Torner, N. et al. Epidemiology of acute gastroenteritis outbreaks caused by human calicivirus (norovirus and sapovirus) in Catalonia: A two-year prospective study, 2010-2011. PLoS ONE 11, e0152503. https://doi.org/10.1371/journal.pone.0152503 (2016).

30. Inns, T. et al. What proportion of care home outbreaks are caused by norovirus? An analysis of viral causes of gastroenteritis outbreaks in care homes, North East England, 2016-2018. BMC Infect. Dis. 20, 2. https://doi.org/10.1186/s12879-019-4726-4 (2019).

31. Steele, M. K. et al. Characterizing norovirus transmission from outbreak data, United States. Emerg. Infect. Dis. 26, 1818-1825. https://doi.org/10.3201/eid2608.191537 (2020).

32. Espenhain, L., Berg, T. C., Bentele, H., Nygård, K. \& Kacelnik, O. Epidemiology and impact of norovirus outbreaks in Norwegian healthcare institutions, 2005-2018. J. Hosp. Infect. 103, 335-340. https://doi.org/10.1016/j.jhin.2019.06.010 (2019).

33. Ahmed, S. M., Lopman, B. A. \& Levy, K. A systematic review and meta-analysis of the global seasonality of norovirus. PLoS ONE 8, e75922. https://doi.org/10.1371/journal.pone.0075922 (2013).

34. Kroneman, A. et al. Analysis of integrated virological and epidemiological reports of norovirus outbreaks collected within the Foodborne Viruses in Europe Network from 1 July 2001 to 30 June 2006. J. Clin. Microbiol. 46, 2959-2965. https://doi.org/10. 1128/JCM.00499-08 (2008).

35. Chen, Y., Hall, A. J. \& Kirk, M. D. Norovirus disease in older adults living in long-term care facilities: Strategies for management. Curr. Geriatr. Rep. 6, 26-33. https://doi.org/10.1007/s13670-017-0195-z (2017).

36. Petrignani, M., van Beek, J., Borsboom, G., Richardus, J. H. \& Koopmans, M. Norovirus introduction routes into nursing homes and risk factors for spread: A systematic review and meta-analysis of observational studies. J. Hosp. Infect. 89, 163-178. https:// doi.org/10.1016/j.jhin.2014.11.015 (2015).

37. Miura, F., Matsuyama, R. \& Nishiura, H. Estimating the asymptomatic ratio of norovirus infection during foodborne outbreaks with laboratory testing in Japan. J. Epidemiol. 28, 382-387. https://doi.org/10.2188/jea.JE20170040 (2018).

38. Rosenthal, N. A. et al. Epidemiological and genetic characteristics of norovirus outbreaks in long-term care facilities, 2003-2006. Epidemiol. Infect. 139, 286-294. https://doi.org/10.1017/S095026881000083X (2011).

\section{Author contributions}

I.P. and A.D. conceptualized and designed the study, carried out the initial analyses and interpretation of data and drafted the initial manuscript. M.A. and C.R.: designed the study and acquisition of data and revised critically the manuscript. T.C.-S. carried out analyses and interpretation of data, performed the laboratory analyses and drafted the initial manuscript. M.J., C.P., I.B. and S.G. contributed to the final analyses and interpretation of data and critically revised the final manuscript. The Working Group for the Study of Outbreaks of Acute Gastroenteritis in Catalonia contributed to the cencept and design of the the study, acquisition of data and critically revised the manuscript. All authors approved the final manuscript as submitted and agree to be accountable for all aspects of the work.

\section{Funding}

This study was funded by Instituto de Salud Carlos III through the project PI16/02005 (Co-funded by European Regional Development Fund "Investing in your future") and the Catalan Agency for the Management of Grants for University (AGAUR Grant No. 2017/SGR 1342). The funders had no role in the design and conduct of the study; collection, management, analysis, and interpretation of the data; preparation, review, or approval of the manuscript; and decision to submit the manuscript for publication.

\section{Competing interests}

The authors declare no competing interests. 


\title{
Additional information
}

Correspondence and requests for materials should be addressed to I.P.

Reprints and permissions information is available at www.nature.com/reprints.

Publisher's note Springer Nature remains neutral with regard to jurisdictional claims in published maps and institutional affiliations.

\begin{abstract}
(c) (i) Open Access This article is licensed under a Creative Commons Attribution 4.0 International License, which permits use, sharing, adaptation, distribution and reproduction in any medium or format, as long as you give appropriate credit to the original author(s) and the source, provide a link to the Creative Commons licence, and indicate if changes were made. The images or other third party material in this article are included in the article's Creative Commons licence, unless indicated otherwise in a credit line to the material. If material is not included in the article's Creative Commons licence and your intended use is not permitted by statutory regulation or exceeds the permitted use, you will need to obtain permission directly from the copyright holder. To view a copy of this licence, visit http://creativecommons.org/licenses/by/4.0/.
\end{abstract}

(C) The Author(s) 2021

\section{the Working Group for the Study of Outbreaks of Acute Gastroenteritis in Catalonia}

Cristina Pérez ${ }^{1}$, Josep Álvarez ${ }^{1}$, Irene Barrabeig ${ }^{1,3}$, Maria Rosa Sala ${ }^{1}$, Anna Isabel Belver ${ }^{1}$, Ariadna Rovira ${ }^{1}$, Ignacio Parrón ${ }^{1,2}$, Lorena Coronas ${ }^{2}$, Miquel Alsedà ${ }^{4}$, Pere Godoy ${ }^{3,4}$, Anna de Andres ${ }^{5}$, Javier de Benito ${ }^{5}$, Esteve Camprubi ${ }^{5}$, Montse Cunillé, ${ }^{5}$ M. Lluïsa Forns ${ }^{5}$, Antonio Moreno-Martínez ${ }^{5}$, Efrén Razquín ${ }^{5}$, Sara Sabaté ${ }^{5}$, Mercé de Simón ${ }^{5}$, Cristina Rius ${ }^{3,5}$, Àngela Domínguez $^{2,3}$, Núria Soldevila ${ }^{2,3}$, Rosa Bartolomé ${ }^{6}$, Thais Cornejo-Sánchez ${ }^{6}$, Mireia Jané2, 3,7, Ana Martínez ${ }^{7}$, Núria Torner ${ }^{7}$, Conchita Izquierdo ${ }^{7}$, Rosa Maria Vileu ${ }^{7}$, Susana Guix ${ }^{8,9}$, Neus Camps $^{10}$, Maria Sabaté ${ }^{10}$, Sofia Minguell ${ }^{11}$ \& Monica Carol ${ }^{12}$

${ }^{10}$ Sub-Direcció Regional a Girona del Departament de Salut, Girona, Spain. ${ }^{11}$ Sub-Direcció Regional a Tarragona del Departament de Salut, Tarragona, Spain. ${ }^{12}$ Sub-Direcció Regional a Catalunya Central del Departament de Salut, Manresa, Spain. 